\title{
Anticipatory Socialization of Students
}

\author{
Based on the Perspective of School Admissions*
}

\author{
Guanghan Zhang \\ School of Business \\ Beijing Institute of Technology, Zhuhai \\ Zhuhai, P.R. China \\ Jianfeng Chen \\ School of Business \\ Beijing Institute of Technology, Zhuhai \\ Zhuhai, P.R. China
}

\author{
Yeyang $\mathrm{Hu}$ \\ School of Business \\ Beijing Institute of Technology, Zhuhai \\ Zhuhai, P.R. China \\ Chih Huang \\ School of Business \\ Beijing Institute of Technology, Zhuhai \\ Zhuhai, P.R. China
}

\begin{abstract}
This study focuses on the anticipation stage of organizational socialization theory, and takes the 2017freshmen of the School of Business of Beijing Institute of Technology, Zhuhai as the research objects, to make an investigation of the school's admission promotion and of freshmen's acknowledge of the school, and the results are revealed that: (1) Half of the students know the school only after they are required to fill the intention for university; (2) Most students know the school from the guidance of intention filling for university; (3) More than half of the freshmen are attracted by the school's regional advantages and environment.
\end{abstract}

Keywords-organizational socialization; anticipatory socialization; admissions promotion

\section{INTRODUCTION}

In the construction of theory, the research of early socialization is proposed to use a stage model for discussion on the process of socialization. The stage model of socialization is to pay attention to and understand the transformation process of newcomers into development into members of the organization to explain the time points of newcomers to learn and change. This view prompted many subsequent empirical studies to adopt a longitudinal research design to explore the change and results of freshmen after joining the organization. This paper introduces this point of view, and divides the socialization of the 2017-freshmen of the Business School of Zhuhai College of Beijing Institute of Technology the following three stages, including anticipation, encounter and adjustment. After passing the college entrance examination, when the students collect university information and think about which university they are going to study in the future, the anticipatory socialization has already begun; and at this stage the freshmen will also develop their expectations for the life and work in the new organization; and they will have a variety of emotions that will be optimistic or negative for future campus life. When

*This article is one of the phased results of the 2017 Innovation and Entrepreneurship Training Program of Beijing Institute of Technology, Zhuhai. (Project code: 3500002/021/005/015). they begin the registration of study in the school, they will make a comparison of everything that they intuitively feel with their expectations, which may be different or in line with their expectations. If the students feel their expectation is failed, there will be many adverse effects such as dropping out of school or transferring to other school. In many studies, it is also believed that experience of early socialization will affect the subsequent attitudes and behaviors of newcomers, and for the anticipatory socialization of students, this paper makes a study and analysis on the problems based on the 2017-freshmen of the business school of Zhuhai College of Beijing Institute of Technology, and proposes better suggestions for the school according to the student questionnaire.

\section{LITERATURE REVIEW}

\section{A. Related Concept Analysis}

1) Socialization: Socialization is the process of interaction between the individual and the society, gradually developing a unique personality and individuality, transforming from a biological person to a social person, and gradually adapting to the social life through the internalization of social knowledge and the learning of role knowledge. Of course, only when accepting and adapting to the society, individuals can play the role of "social role", engage in "social interaction" and participate in various "social groups" and "social organizations".

The socialization of people is one of the basic concepts of sociology. The socialization in sociology is not the same as the socialization of production, the socialization of logistics, and the socialization in guarantee that people often refer to in daily life. The latter mainly refers to the centralization, unification and standardization of people's activities in certain aspects, and it is a trend of social life development, while the socialization in sociology refers to the process in which a person as individuals grows into a social person. 
German sociologist G. Zimel first used the concept of "socialization" in 1895, and he used the "socialization" in the article "Issues of Sociology" to describe the problem of group formation. From then, the study of human socialization is not only an important topic of sociology, but also as a topic related to sociology, gradually gets much attention jointly from many interdisciplinary subjects such as social psychology, cultural anthropology, educational sociology, etc., which explore the socialization of people from different perspectives. Thus, with the development of sociology and these interdisciplinary subjects, there have been many definitional understandings of "socialization of people", such as the American sociologist C. Curry and the American psychologist G. Meade who take the socialization of people as the process of forming and developing a social individual; the American sociologist W. Ogben who understands it as the process of accepting and inheriting social culture and continuing social life; the American sociologist S. Sargent and T $\bullet$ Parsons who interprets it as the process of making people more social through role learning to achieve role-bearing; the Chinese sociologist Fei Xiaotong who believes it is the "process of a person learning knowledge, skills and norms, and getting qualifications for social life, and developing his/her social character"; and the Chinese scholars Yang Xinheng, Zong Li, Huang Yufu et al think it as the process of adapting to the social environment and social life under the social induction.

\section{2) Organizational socialization: Organizational} socialization is a very important stage in the process of individual socialization. This paper believes that socialization is not just a process of transforming from a biological person to a social person. Socialization is not a special process that tends to a certain stage, but a process that runs through the whole life. From the perspective of culture, socialization is the process of continuing and spreading culture, and is the internalization of value standards. From the perspective of personality development, socialization is the process of the formation and development of human personality. Through the contact with society, we gradually develop unique hobbies that are different from others, and constantly adjust ourselves according to the expectations of society. In the process of socialization, we gradually understand our positions in the social structure, learn to successfully fulfill the role obligations, and understand and abide by the society's expectations for these roles. Socialization helps to maintain and develop social structures. University is also a form of social organization, and changing from the role of middle school students to the new role of college students also needs to be learned and adapted for the freshmen. Therefore, this paper takes the 2017 freshmen of the School of Business of Beijing Institute of Technology, Zhuhai as the survey objects, and analyzes and studies the problems in the encounter period of college students' socialization.

\section{B. Stage of Socialization}

In early socialization researches, it has been proposed that the process of socialization should be discussed in stages in the construction of theories. The stage model of socialization is to explain the time points for newcomers to learn and change by paying attention to and understanding the process of newcomers changing and developing into members of the organization. This view has prompted many subsequent empirical studies to adopt a vertical research design to explore the degree of change and changing results of newcomers after they have been in an organization for a period of time. This paper introduces the viewpoint of the stage model of organizational socialization, and divides the socialization of the 2017 freshmen of the School of Business of Beijing Institute of Technology, Zhuhai into three stages: anticipation socialization, encounter period and adjustment period. This article will focus on the relevant content of the anticipation socialization stage.

1) Anticipation socialization: Many scholars believe that this stage occurs when newcomers are ready to enter the organization, and all their learning takes place before they have joined the organization. Newcomers develop their own cognitive maps on the basis of their past experience. The cognitive maps provide them with ways to interpret new situations and ways of sense-making, so newcomers' past experience has an adjustment effect on the events happened in new work environments. In other words, when college freshmen collect university information after the college entrance examination and think about which university they are going to study in the future, anticipation socialization has already begun. At this stage, students are separated from the original simple and passive campus environment and receive admission information from various universities. At the same time, students will take the initiative to look for the information they need, such as understanding the university's consumption level and accommodation conditions by contacting with senior students in the same town.

In addition, at this stage, newcomers will also develop expectations for their life and work in the new organization[1]. At this stage, students will generate optimistic or negative attitudes about their future campus life. When the new term begins and they come to universities to register, the students will compare everything they feel intuitively with what they have expected before. The actual situation may be different from their expectations or in line with their expectations. If the student feels that his or her expectations have failed, he or she will possibly drop out of school or transfer to another school. Many scholars also believe that early socialization experiences will affect the follow-up attitudes and behaviors of newcomers. Therefore, when there are differences between reality and expectations, what should the school and the students do? And what kind of attitude should they have to face the situation? Those are the problems to be faced and dealt with in the next stage of socialization - the encounter period. 


\section{EMPIRICAL INVESTIGATION}

\section{A. Investigation Procedure}

In order to make the research process rigorous, there were three research methods used in this study to organize and analyze the data. First, the literature analysis method. We have collected the theories about socialization through various ways and made them as the theoretical basis of this research. The group members have read and discussed relevant materials to determine the research direction and purpose. Secondly, the interview survey method. For the freshmen of the school of business of Beijing Institute of Technology, Zhuhai, we have interviewed the representatives of each class of the seven majors of the school of business (the number of interviewers was 35), summarized the interview contents, and written an interview report. Finally, the questionnaire survey method. The research team has repeatedly discussed and summarized the interview report, drafted the preliminary questionnaire, and conducted a pre-test (30 samples). After ensuring the correctness and validity of the questionnaire, we have conducted a large-scale questionnaire survey on the 2017 freshmen of the school of business. A total of 707 questionnaires were distributed and 516 questionnaires were effectively recovered. The effective recovery rate was $72.98 \%$.

\section{B. Sample Characteristic Analysis}

As this study takes the 2017 freshmen of the School of Business of Beijing Institute of Technology, Zhuhai as the survey respondents, from the gender point of view, there are 189 boys in the sample of this survey, accounting for $37.4 \%$; 316 girls in the sample, accounting for $62.6 \%$. It can be seen that the majority of the respondents are girls. From the speciality point of view, the respondents are mostly from the international economics and trade speciality, with a total of 95 students, accounting for $18.9 \%$, ranking first; followed by the logistics management speciality, with a total of 90 students, accounting for $17.9 \%$; the third is the marketing speciality, with a total of 78 students, accounting for $15.5 \%$.

\section{Statistical Analysis Results}

Based on the purpose of this study, this article will analyze the data from two aspects: the initial understanding of the school and the impression of the school before entering the school.

\section{A. Understanding of the School}

Under normal circumstances, students will learn about the conditions of the chosen university through various channels after they have applied for the university and have been accepted. The campus situation that students learn before entering the school often determines whether students will be anxious and uncomfortable when they first enter the university. The following are the survey analyses on how the students learned about the school, how they felt about the school before entering the school, and why they have chosen the school and the major, to make us master the students' understanding of the school before they have entered the school.

TABLE I. The Time Point of INITIALly KNOWING THE SCHOOL

\begin{tabular}{lllll}
\hline \multicolumn{1}{c}{ Options } & $\mathbf{N}$ & $\begin{array}{c}\text { Effective } \\
\text { Percentage } \\
(\%)\end{array}$ & \multicolumn{1}{c}{$\begin{array}{c}\text { Cumulative } \\
\text { Percentage (\%) }\end{array}$} \\
\hline $\begin{array}{l}\text { Before the college } \\
\text { entrance examination }\end{array}$ & 144 & 28.0 & 28.0 \\
$\begin{array}{l}\text { Before signing up the } \\
\text { chosen university }\end{array}$ & 141 & 27.4 & 55.3 \\
$\begin{array}{l}\text { When signing up the } \\
\text { chosen university }\end{array}$ & 230 & 44.7 & 100.0 \\
\hline Total & 515 & 100.0 & \\
\hline
\end{tabular}

As can be seen from "Table I", $44.7 \%$ of the students were informed of the school when they needed to fill in their target schools. It can be seen that nearly half of the students learned about the school only when they needed to fill in their target schools. On the contrary, only $28.0 \%$ of the students already knew about the school before the college entrance examination. Therefore, the enrolling publicity effect of our school in various high schools is not obvious, and there is still much room for improvement.

TABLE II. CHANNELS OF LEARNING ABOUT THE SCHOOL

\begin{tabular}{llll}
\hline \multicolumn{1}{c}{ Options } & $\mathbf{N}$ & $\begin{array}{c}\text { Effective } \\
\text { Percentage } \\
(\boldsymbol{\%})\end{array}$ & $\begin{array}{c}\text { Percentage } \\
\text { of Cases } \\
(\boldsymbol{\%})\end{array}$ \\
\hline $\begin{array}{l}\text { College Entrance Examination } \\
\begin{array}{l}\text { University Choosing Guide } \\
\text { University choosing guidance }\end{array}\end{array}$ & 333 & 38.4 & 64.8 \\
$\begin{array}{l}\text { magazines and newspapers } \\
\text { Teacher recommendation }\end{array}$ & 84 & 9.7 & 16.3 \\
$\begin{array}{l}\text { Family or relatives informing } \\
\text { Friends informing }\end{array}$ & 128 & 3.6 & 6.0 \\
Campus presentation & 117 & 13.5 & 24.9 \\
The internet & 30 & 3.5 & 22.8 \\
Others & 128 & 14.7 & 5.8 \\
\hline Total & 17 & 2.0 & 24.9 \\
\hline
\end{tabular}

It can be seen from "Table II" that the number of students who learned about the school from the College Entrance Examination University Choosing Guide is the largest, accounting for $38.4 \%$. The number of students who were informed of the school by the family or relatives or through the Internet is the second largest, accounting for $14.7 \%$. $13.5 \%$ of the students were informed of the school by their friends. It can be seen that in the channels of learning about the school, learning from the College Entrance Examination University Choosing Guide is the most important way, and family members or relatives informing, knowing from the Internet and friends informing are also very important channels. On the contrary, the proportion of students knowing the school from teacher recommendation and campus presentations is very low, at $3.6 \%$ and $3.5 \%$ respectively. It can be seen that the enrolling publicity effect of the school admissions office in the major high schools is not as good as expected. 
TABLE III. REASONS FOR CHOOSING THIS SCHOOL

\begin{tabular}{llll}
\hline \multicolumn{1}{c}{ Options } & N & \multicolumn{1}{c}{$\begin{array}{c}\text { Effective } \\
\text { Percentage } \\
(\boldsymbol{\%})\end{array}$} & $\begin{array}{c}\text { Percentage } \\
\text { of Cases (\%) }\end{array}$ \\
\hline $\begin{array}{l}\text { Good urban environment } \\
\begin{array}{l}\text { Regional advantages (near } \\
\text { Hong Kong and Macao, }\end{array}\end{array}$ & 232 & 24.5 & 45.2 \\
$\begin{array}{l}\text { developed economy) } \\
\begin{array}{l}\text { Attracted by the name of } \\
\text { the school }\end{array}\end{array}$ & 72 & 7.6 & 53.4 \\
$\begin{array}{l}\text { Teacher recommendation } \\
\text { Recommended by relatives } \\
\text { and friends }\end{array}$ & 37 & 3.9 & 14.0 \\
$\begin{array}{l}\text { Recommended by alumni } \\
\text { of this school }\end{array}$ & 31 & 11.2 & 7.2 \\
$\begin{array}{l}\text { Parents recommendation } \\
\text { Others }\end{array}$ & 85 & 9.0 & 20.7 \\
\hline Total & 109 & 11.5 & 6.0 \\
\hline
\end{tabular}

It can be seen from "Table III" that the number of people who have chosen this school because of its regional advantages (near Hong Kong and Macao, the economy is developed) is the largest, accounting for $29.0 \%$. The students who have chosen this school because of the good urban environment account for $24.5 \%$. It can be seen that the urban environment and regional advantages are more important for students to choose a school. The number of students who have chosen this school as recommended by its alumni is the smallest, accounting for only $3.3 \%$. It can be seen that although the alumni recommendation is an effective and important channel, the alumni of this school have obviously not played much of the role of publicity.

TABLE IV. REASONS FOR STUDENTS TO CHOOSE A SPECIALITY

\begin{tabular}{|c|c|c|c|}
\hline Options & $\mathbf{N}$ & $\begin{array}{c}\text { Effective } \\
\text { Percentage } \\
(\%)\end{array}$ & $\begin{array}{c}\text { Percentage of } \\
\text { Cases }(\%)\end{array}$ \\
\hline Interest & 178 & 24.4 & 34.6 \\
\hline Teacher recommendation & 18 & 2.5 & 3.5 \\
\hline $\begin{array}{l}\text { Recommended } \\
\text { relatives and friends }\end{array}$ & 93 & 12.7 & 18.1 \\
\hline $\begin{array}{l}\text { Good employment } \\
\text { prospects }\end{array}$ & 207 & 28.3 & 40.2 \\
\hline $\begin{array}{l}\text { Few choices of majors in } \\
\text { their provinces }\end{array}$ & 41 & 5.6 & 8.0 \\
\hline Be adjusted & 86 & 11.8 & 16.7 \\
\hline Does not matter & 63 & 8.6 & 12.2 \\
\hline Others & 45 & 6.2 & 8.7 \\
\hline Total & 731 & 100.0 & 141.9 \\
\hline
\end{tabular}

"Table IV" shows the reasons why students choose their majors. $28.3 \%$ of students chose their majors because of good employment prospects. Students who chose majors because of their interests account for $24.4 \%$. $12.7 \%$ of students chose their majors because of the recommendation of relatives and friends. $11.8 \%$ of students chose their majors because of being adjusted. Secondly, students who do not care about the major and chose their majors for other reasons account for $8.6 \%$ and $6.2 \%$ respectively. And only $2.5 \%$ of students chose their majors because of teacher recommendation. It can be seen that the 2017 freshmen have clear goals and plans for their future employment. They are not blindly choosing their majors.
B. Initial Impressions of the School

TABLE V. PRELIMINARY IMPRESSIONS OF THE SCHOOL BEFORE ENTERING THE SCHOOL

\begin{tabular}{llll}
\hline \multicolumn{1}{c}{ Options } & $\mathbf{N}$ & \multicolumn{1}{c}{$\begin{array}{c}\text { Effective } \\
\text { Percentage } \\
(\boldsymbol{\%})\end{array}$} & $\begin{array}{c}\text { Percentage } \\
\text { of Cases } \\
(\boldsymbol{\%})\end{array}$ \\
\hline Good environment & 250 & 20.3 & 48.6 \\
Large campus area & 280 & 22.7 & 54.5 \\
Strict school spirit & 28 & 2.3 & 5.4 \\
Convenient & 157 & 12.8 & 30.5 \\
transportation & 419 & 34.0 & 81.5 \\
High tuition & 25 & 2.0 & 4.9 \\
Little learning pressure & 44 & 3.6 & 8.6 \\
Good teachers & 28 & 2.3 & 5.4 \\
Others & 1231 & 100.0 & 239.5 \\
\hline Total & & & \\
\hline
\end{tabular}

According to the data in "Table V", $34.0 \%$ of the students think that the school tuition is high, and the proportion is the highest. Students who believe that the school has a large area and good environment account for $22.5 \%$ and $20.3 \%$ respectively. Among them, $12.8 \%$ of the students believe that there is convenient transportation in the school. It can be seen that the 2017 freshmen have a deep impression on the school's high tuition fees, good environment and large floor space before entering the school. It can also be drawn from the data that the school should be upgraded in terms of traffic control, school spirit building, and teacher employment, which will be conducive to expanding the source of students.

\section{CONCLUSION AND RECOMMENDATIONS}

\section{A. Conclusion}

- Freshmen know very little about the school before they fill in their target universities. Most of the freshmen get to know the school when they need to fill in their target universities, and they mainly learn about the school through the college entrance examination university choosing guide.

- More than $10 \%$ of freshmen know the school from family members, friends, and the Internet.

- Most of the freshmen chose the school because it has geographical advantages and the urban environment is good. However, there are fewer students who chose the school because of its name and other people's recommendations or suggestions.

- Most of the freshmen chose their majors because of good employment prospects and personal interests. A few freshmen chose their current majors because they were recommended by relatives and friends or they were adjusted to current majors.

- Most of the freshmen were most impressed with the high tuition fees of the school before entering the school. They had deep impressions on the school's large floor space, good environment and convenient transportation, and had few impressions on the 
school's school spirit, learning pressure and teacher teams.

- About half of the freshmen think that the actual environment of the campus, the floor space and the buildings and equipment are in line with their previous impressions, but there are also a few freshmen who think that those above do not conform to their previous impressions, so there is still room for improvement in all aspects for the school.

- Most of the freshmen think that their actual freedom in the school, community life, friendship, love situation, independent living, conscious learning, interpersonal relationship and less loneliness are consistent with their previous imaginations, a few freshmen think that their study conditions at the school and the dormitory conditions do not match their previous imaginations.

\section{B. Recommendations}

Through the questionnaire survey, we can know that the most attractive thing of the school is the regional advantage, and the second most attractive thing is the urban environment. The initial impression of most students on the school is that the tuition is high. This article believes that in the promotion of admissions, the school admissions office can develop strengths and avoid weaknesses, focus on promoting the information that students and parents like, and reduce the propaganda of the information that is not so conducive to admissions, but the school admissions office must tell the students about the information. With regard to students' anticipation socialization - school admissions promotion, this article has provided the following suggestions:

- It is possible to encourage the students of the school to return to their high schools and publicize the university.

- The university can hold presentations in the high schools in its province.

- In the case of relatively high tuition fees, students can be provided with a better learning environment, the school should pay attention to the students' suggestions, so that students and parents will feel that the tuition fees are worth being paid.

When students are choosing their majors, the school can provide more detailed introductions about each major to help students choose their majors more correctly.

\section{REFERENCES}

[1] Louis, M. R. 1980. Surprise and sense making: What newcomers experience in entering unfamiliar organizational setting. Administrative Science Quarterly, 25: pp.226-251.

[2] Feldman, D. C. 1981. The multiple socialization of organization members. Academy of Management Review, 6: pp.309-319.

[3] Van Maanen, J. 1975. Police socialization: A longitudinal examination of job attitudes in an urban police department. Administrative Science Quarterly, 20:pp.206-228.
[4] Buono, A. F., \& Kamm, J. B. 1983. Marginality and the organizational socialization of female managers. Human Relations, 36: pp. $1125-1140$.

[5] Dubinsky, A. .J., Howell, R. D., Ingram, T. N., \& Bellenger, D. N. 1986. Sales force socialization. Journal of Marketing, 50: pp.192-207.

[6] Reichers, A. E. 1987. An interactionist perspective on newcomer socialization rates. Academy of Management Review, 12: pp.276-287.

[7] Van Maanen, J., \& Schein, E. H. 1979. Toward a theory of organizational socialization. Research in Organizational Behavior, 1: pp.209-264.

[8] Bauer, T. N., Morrison, E. W., \& Callister, R. R. 1998. Organizational socialization: A review and directions for future research. In G. R. Ferris (Ed.), Research in Personnel and human resources management, 16: pp.149-214. Greenwich, CT: JAI Press.

[9] Bauer, T. N. \& Green, S. G. 1998. Testing the combined effects of newcomer information seeking and manager behavior on socialization. Journal of Applied Psychology, 83(1): pp.72-83.

[10] Feldman, D. C. 1976. A contingency theory of socialization. Administrative Science Quarterly, 21: pp.433-452.

[11] Jones, G. R. 1986. Socialization tactics, self-efficacy, and newcomers' adjustments to organizations. Academy of Management Journal, 29(2): pp.262-279. 